\title{
THE ESSENCE OF SCHOOL EDUCATION
}

\author{
M. Teneva* \\ Faculty of Education, Trakia University, Stara Zagora, Bulgaria
}

\begin{abstract}
Studying in an organized form of education is a focused and rational process aimed at the acquisition of the social experience in a systematic and summarized way. This process has the potential to lead to progressive and relatively permanent changes in the personality. The future functions of the individual in the society require an even more effective organization of studying in an organized form of education, the use of even more sophisticated methods and techniques, as well as tight connection between education and life.

The aim of the present study is to establish what the quality of school education is, according to the self-evaluation of the high-school graduates.

In order to achieve the aim, a questionnaire is used.

The results show that the high-school graduates evaluate their secondary education as not efficient enough.

In order to raise its effectiveness, there is a need to reconsider the whole paradigm of secondary education.
\end{abstract}

Key words: school studying, effectiveness of school studying, quality of school studying

\section{INTRODUCTION}

According to the results of the international evaluation of school students PISA, initiated by the Organization of economic cooperation and development, in which 5280 students from 188 schools throughout Bulgaria took part, the education of our children is not among the most effective ones in the world. The leading positions are taken by Shanghai-China, Hong Kong, China and Singapore. Among the surveyed 65 countries/regions in the world, Bulgaria ranks at 45th position in science literacy, at position 47 in math and position 51 in reading literacy (1). These results not only do not bring us pride, but are actually a rather worrying fact.

No less disturbing is the information, according to which in 2013 the lowest test results of the external evaluation after the fourth grade were registered. The provided statistics says that $80 \%$ of the fourth graders have successfully covered the state standards from 2007 to 2013, registering a decline in the level of success. A regression in the achievements of Bulgarian students at the end

\footnotetext{
* Correspondence to: Maria Teneva

Faculty of Education, Trakia University - Stara

Zagora, Bulgaria,m.s.teneva@abv.bg
}

of the initial stage of primary education was established, the lowest values being in 2013.

The statistical data show that $80 \%$ of the State standard was covered in 2007 by $81,1 \%$ of the fourth graders; in 2008 - by $80,5 \%$; in $2009-$ by $74,7 \%$; in 2010 - by $71,5 \%$; in 2011 - by $70,5 \%$; in 2012 - by $72,65 \%$; in 2013 - by $67,5 \%(2)$.

The disturbing fact based on the reported drop in the achievements of Bulgarian students provoked us to seek answers to some important questions. What is being made about the problems identified in the field of education? Is the Bulgarian school being reformed?

\section{METHODOLOGY}

To find out what the opinion of high school graduates on the quality of school learning is, we developed and approbated a questionnaire for self-evaluation.

The study covered first year students who are being trained at the Faculty of Education of Trakia University in Stara Zagora.

All the questions in the questionnaire require individual answers. 
To ensure greater impartiality and credibility of the responses to the questions, the test was given to be filled in anonymously.

The contingent of the respondents was selected randomly. For us as educators it is important to determine how the future teachers themselves assess the quality of their secondary education, what the shortcomings of school learning are.

\section{THE ESSENCE OF SCHOOL EDUCATION}

School learning has many advantages compared with natural learning. We should not underestimate the undeniable merits of natural learning. Some of them are: high intrinsic motivation, individual studying, research and discovery.

Learning in the conditions of organized education is characterized by compulsion, as it is externally motivated. The transition from external to internal motivation is sometimes elusive and not very susceptible to deliberate regulation.

Considering the unity "teaching-learning", the primary and fundamental process is that of learning. The pace of the progressive changes taking place in the individual depends mostly on the quality of the organization of this unity.

More and more educators promote the understanding that learning in an organized form of education should help to shape the following: knowledge - information, intellectual skills, cognitive strategies, motor skills, attitudes. This formal content of studying should be placed at the base of the formation of the learning objectives.

The process of learning in an organized form of training is a dialectical one and produces qualitative changes in the student on the basis of overcoming the contradictions between the old and the new states, old and new knowledge, skills and experience. Learning is an effective way towards a whole structuring and restructuring of the mental powers, abilities, knowledge and experience of the student, where each preceding phase is contained in the next, each lower stage is a prerequisite for the formation of the higher ones.

L. Dobson said the following: "In my dictionary the verb teach is defined as passing on knowledge or skills to someone; give instructions, directions to someone. According to this definition, the trainee is simply a passive receiver of the actions of the teacher" (3).

Unfortunately, this is the conventional understanding of the nature of learning among the majority of educators. Very often in their professional activities they put the student in a passive position, trying to "pass" him ready-touse knowledge. Education is consistent with the school plan and the school curriculum. The teacher decides what teaching materials to use, what pieces of knowledge to be taught in the specific classes, how to present them to the students. The role of the student is reduced to being a passive "receiver " of this information, after which he or she has to show the extent to which they have memorized the answer of the questions, to correctly reproduce the lesson at an oral examination and when making tests.

Starting from the fact that learning in the conditions of organized education is a purposeful process, should make it clear what to focus its objectives on.

The pursuing of a goal is a characteristic of the person to show perseverance, determination and rigor in his or her behavior. It is seen as the antithesis of superficiality, impulsiveness, changeability. Goal setting is a formulation of goals and objectives, which are the embodied component of an event.

According to Pl. Radev, learning objectives can be viewed in two ways: as a construct and as an event (4).

The educational purpose as a construct is the perfect image of the result of education.

The educational purpose as an event is an integrating element of the activities in educational and training events.

The common goals are those that are set out in the regulations - the Public Education Act, the Rules for Implementation of the Law on Public Education, the Law for the education minimum curriculum and degree of education.

The general objectives are those set by the individual school. They must be in unity with the common goals. They are determined in accordance with the mission of the school and the stages and levels of education that it provides.

The objectives of the school are ideally a prediction of the outcome of its activities. They are an objective model of operation to which an organization (school) aspires, a structured vision of the relationship between the demands 
of the consumers of the educational products and services and the means for meeting them.

Specific learning objectives are those which are designed to address the individual subjects of a cultural and educational field.

Concrete learning objectives are those of an organizational form of training - different types of lessons, seminars, laboratory work, workshops, training and others.

Clarifying the problem about the goals of the learning process, we should have in mind that it should be in conformity with its nature, which is characterized by the following: the acquisition of knowledge, acquisition of skills, the formation of ways of learning, the development of skills and competencies, as well as the overall shaping of the personality of the trainees.

The exact formulation of the objectives also includes the minimum accepted standards for absorption and improvement of the behavior after the training or towards its end. The standard points at how the observed behavior must be demonstrated so that it can be seen and appreciated.

The standard can be presented in both quantitative and qualitative terms, depending on its content. Quality standards include a description of the minimum elements that the student should master at the end of the training. (5)

The experts in the relevant subject areas determine by what standard the observable or unobservable behavior of criteria will be assessed.

If the final behavior is not described in detail by the minimum accepted standard, it is not possible to reliably assess it, and the student may not know exactly what level of preparation he or she has achieved.

Rrecently, there has been an alarming trend of Bulgarian students ranking at lower positions in terms of success among the other countries in Europe and worldwide. This fact inspired us to think and to seek answers to some key questions:

Can we define school learning as effective and if so - how effective is it?

Does the educational process help sufficiently the personal development of each individual student?

How can we optimize the learning process in order to increase its effectiveness?
The low scores of our students are not a recent fact. Bulgaria's leading position in Europe is not only for poor students, but also in the number of school dropouts.

It is true that the Bulgarian educational system is too conservative. Furthermore, the cumbersome and not always effective reforms carried out by the Ministry of Education are faced with the reluctance of the majority of practitioners in education to use new methods and techniques in their work, which would contribute to greater efficiency of school learning.

The quality of education has a direct projection on the economic prosperity of society, and this, in turn, on the quality of life. Therefore, we must not leave the above questions unanswered.

\section{RESULTS}

The results of the approbated with first-year students of the Faculty of Education of Trakia University questionnaire outline some important features of school learning and teaching.

The future teachers were given the opportunity to identify which are the most important advantages of school that make it preferred to natural learning.

According to $48 \%$ of the surveyed people, the biggest advantage of learning in the conditions of institutional education is that at school specific knowledge is mastered.

When answering, $45 \%$ of the students indicated that schooling provides good conditions for the establishment of the social contacts of the person.

A share of $35 \%$ are the answers, according to which the value of school learning is that it provides an opportunity to shape a sense of community, skills for teamwork, satisfaction from cooperative activities with other people their age.

$33 \%$ of the responses underline the opportunity of interpersonal interaction with the teachers who are defined as authoritative mediators between scientific knowledge and the personality of the student.

The total percentages exceed 100 because the respondents were able to construct more than one answer. 
The future teachers were given the opportunity to identify factors that have a negative impact on the effectiveness of school education.

Among these factors, $62 \%$ of the respondents indicated a lack of connection between learning and life. They point out that the school does not focus on the applicability of scientific knowledge in a practical manner. Teachers are guided in their professional activity by the principle "learning to know", rather than the principle "learning to act". This reduces the effectiveness of the education which school institutions provide.

In $70 \%$ of the cases, it was indicated that the personality of the teacher should be seen as an important factor influencing the effectiveness of training.

$43 \%$ of the respondents share the opinion according to which the school does not welcome diversity. The school is trying to unify and make the students the same. Teachers work with a formed in their mind image of "the perfect student" who is diligent, studious, obedient, intelligent and perceptive. The teacher would like to work with the student of the type "plastic material" which can be susceptible to manipulation, to influences and treatment without opposition and which can adopt a form that the teacher himself wants to give it. The fact that the human person is truly unique and that his value lies precisely in this is not taken into account. The fact that the natural reaction of the personality of the student is to counter what he does not like in school is also ignored; that even under the same pedagogical interaction the same results for all students cannot be expected. This is a very substantial negative aspect of the Bulgarian educational system which we believe to some extent was inherited from the totalitarian social order in which individuals were not entitled to their own thinking and personal nature.

The future teachers were given the opportunity to do a self-assessment of the effectiveness of their secondary education, using the ascending scale of 1 to 10 .

The results indicate that the surveyed individuals assess their secondary education as not highly effective.

In none of the cases of self-assessments were there assessments in the range of the scale 1, 2or 3. The peak values were recorded in the range of the value $7-27 \%$ of the respondents assessed their secondary education thus. In the range of 8 are $24 \%$ of the answers. $12 \%$ of the future educators assess their secondary education with a value of 9 , only $6 \%$ - with 10 and the remaining percentages to $100 \%$ are equally divided (by 12\%) between level 4 . and 5., and $7 \%$ - in the value 6 .

We have in mind the fact that the respondents were not randomly selected from the general public, but are individuals who have been selected for training at the university, based on their achievements from secondary level. Otherwise, the results would be with much lower values.

\section{CONCLUSION}

Education is essential for the development and self-realization of the individual. On its quality and efficiency depends not only the prosperity of the individual, but also the quality of life and the progress of the whole society.

In this respect it is important that the school provides high quality education services. The training should be based on the humanistic and personal approach. The student should be seen by the teacher as a unique individual and equal to the others in the learning process. The student is to be provoked and encouraged to seek and find practical projections of academic knowledge, to be stimulated and supported his initiative, creativity, uniqueness.

This type of training would move our country to a leading position among the countries with a high quality of education and a fast developing economy.

\section{REFERENCES}

1. International Student Assessment PISA http://www.ckoko.bg/upload/docs/201312/PISA_2012.pdf (14.02.2014)

2. Results-after-test-IV-class/ Results of the test after the IV-th class http://akademika.bg/2013/06/\%D0\%BD\%D 0\%B0\%D0\%B9\%D0\%BD\%D0\%B8\%D1 $\% 81 \% \mathrm{D} 0 \% \mathrm{BA} \% \mathrm{D} 0 \% \mathrm{~B} 8 \% \mathrm{D} 1 \% 80 \% \mathrm{D} 0 \% \mathrm{~B}$ $5 \% \mathrm{D} 0 \% \mathrm{~B} 7 \% \mathrm{D} 1 \% 83 \% \mathrm{D} 0 \% \mathrm{BB} \% \mathrm{D} 1 \% 82 \%$ $\mathrm{D} 0 \% \mathrm{~B} 0 \% \mathrm{D} 1 \% 82 \% \mathrm{D} 0 \% \mathrm{~B} 8$ $\% \mathrm{D} 0 \% \mathrm{~B} 7 \% \mathrm{D} 0 \% \mathrm{~B} 0$ $\% \mathrm{D} 1 \% 82 \% \mathrm{D} 0 \% \mathrm{~B} 5 \% \mathrm{D} 1 \% 81 \% \mathrm{D} 1 \% 82 \% \mathrm{D}$ 0\%B0\%D1\%81\%D0\%BB\%D0\%B5\%D0\% B4-iv-\%D0\%BA\%D0\%BB\%D0\%B0/ (14.02.2014)

3. Dobson, L. Effective learning. IK S. "Lik", p. 10,2006

4. Radev, Pl. General school didactics, Plovdiv. University Press "Paisii Hilendarski, pp.206-208, 2005

5. State educational requirements (Decree № 2 of 18.05.2000) 
Trakia Journal of Sciences, Vol. 13, № 3, 2015 